\title{
Design and Parametric Simulation of a Bi-Band Miniaturized PIFA Antenna for the GSM900 and DCS1800 Bands
}

\author{
Abdelhakim Elouadih ${ }^{1}$, Ahmed Oulad-Said ${ }^{1}$, Moha Mrabet Hassani ${ }^{2}$ \\ ${ }^{1}$ Department of Electrical and Telecommunications Engineering, Royal Air Academy (ERA), Marrakesh, Morocco; ${ }^{2}$ Department of \\ Physics, Semlalia University of Sciences (FSSM), Marrakesh, Morocco. \\ Email: elouadih@gmail.com, a_ouladsaid@hotmail.com, hassani@ucam.ac.ma
}

Received February $26^{\text {th }}, 2013$; revised March $28^{\text {th }}, 2013$; accepted April $11^{\text {th }}, 2013$

Copyright (C) 2013 Abdelhakim Elouadih et al. This is an open access article distributed under the Creative Commons Attribution License, which permits unrestricted use, distribution, and reproduction in any medium, provided the original work is properly cited.

\begin{abstract}
This paper describes the design and simulation by HFSS simulator of a probe-fed Planar Inverted-F Antenna (PIFA) for the use in GSM900 band [890 MHz - $960 \mathrm{MHz}$ ] and DCS1800 band [1710 MHz - $1880 \mathrm{MHz}$. A methodology based on parametric simulations (parameters are ground plan lenght, height of radiating plate, feeding point position, shorting plate width and position) was used to design optimized antenna. The simulation allowed the characterization of the designed antenna and the computing of different antenna parameters like $S_{11}$ parameter, resonant frequency, VSWR, bandwidth, impedance in feeding point, gain, diagram pattern and Fields distribution. The results were very interesting and respect the GSM requirements.
\end{abstract}

Keywords: GSM; DCS; HFSS; PIFA; Patch Antenna; Parametric; Simulation

\section{Introduction}

Wireless communications have progressed very rapidly in recent years, and many mobile units are becoming smaller and smaller. To meet the miniaturization requirement, the antennas employed in mobile terminals must have their dimensions reduced accordingly. Planar antennas, such as microstrip and printed antennas have the attractive features of low profile, small size, and conformability to mounting hosts and are very promising candidates for satisfying this design consideration. Planar antennas are also very attractive for applications in communication devices for wide mobile telecommunications like GSM, wireless local area network, aeronautics and embedded systems [1].

For optimum system performance, the antennas must have high radiation efficiency, small volume, isotropic radiation characteristics, small backward radiation, simple and low-loss impedance matching to patches. The major types of configurations of low-profile antennas with enhanced bandwidth performance include planar inverted F Antennas.

The PIFA consists in general of a ground plane, a top plate element, a feed wire attached between the ground plane and the top plate, and a shorting wire or strip that is connected between the ground plane and the top plate.

The antenna is fed at the base of the feed wire at the point where the wire connects to the ground plane. The PIFA is an attractive antenna for wireless systems where the space volume of the antenna for wireless systems where the space volume of the antenna is quite limited. It requires simple manufacturing, since the radiator must only be printed. The addition of a shorting strip allows good impedance match to be achieved with a top plate that is typically less than $\lambda / 4$ long. The resulting PIFA is more compact than a conventional half-wavelength probefed patch antenna [2].

The miniaturization can affect radiation characteristics, bandwidth, gain, radiation efficiency and polarization purity. The miniaturization approaches are based on either geometric manipulation (the use of bend forms, meandered lines, PIFA shape, varying distance between feeder and short plate [3]) or material manipulation (Loading with a high-dielectric material, lumped elements, conductors, capacitors, short plate [4]) or the environment characteristics (ground plane dimensions, coupling, measurement and fabrication errors [3]). In this case, the bi-band designed antenna is shorted to the ground plane by a plate, uses regular shapes and uses a 
high dielectric thin substrate under the radiating plate not above the ground plane).

If all precedent works are concentrated on studying the effects of these elements (material, geometry, environment), the choice of a PIFA element was so improvised in the design. In this paper, a methodology based on parametric simulation is used to choose simultaneously or independently different PIFA elements and the results should be compliant for both bands.

In the next section, the author presents the methodology and detailed parametric simulations to optimize the antenna design. After, the dimensions and parameters are then chosen. The author exposes in the third section the characteristics of the designed antenna.

\section{Design Methodology}

\subsection{The Description of the Studied Antenna}

As shown in Figure 1, the designed antenna has a rectangular radiating patch length $\mathrm{Lp}=29.3 \mathrm{~mm}$ and width $\mathrm{Wp}=64 \mathrm{~mm}$. the patch is placed at a height $\mathrm{h}$ from the ground plan. The patch has a length $\mathrm{Lg}$ and a width $\mathrm{Wg}$ equal to $\mathrm{Wp}$. The patch is matched to the ground plan via a rectangular shorting plate. The shorting plate has a width Ws and a length $h$. The shorting post of usual PIFA types is a good method for reducing the antenna size, but results in narrow impedance bandwidth. It is placed in the (yz) plan at a distance D from the edge centre. The the feeding point is situated at $\mathrm{p}$ from the rear edge of the patch. The patch is fed by a $50 \Omega$ wire, a semi-rigid coax with centre conductor that extends beyond the end of the outer conductor is used to form the PIFA feed wire. The outer conductor of the coax is soldered to the edge of a small hole drilled in the ground plane at the feed point. The volume between the radiating plate and the ground plan is filled by air except a thin region $0.8 \mathrm{~mm}$ under the radiating patch who is composed of FR4 epoxy $\left(\varepsilon_{r}=4.4\right)$.

\subsection{The Choice of the Patch Dimensions}

It is very important for simulation by HFSS to estimate the resonant frequency that help the simulator to make a refinement mesh in a band around the resonant frequency and then give more precise values. The resonant frequency of a PIFA is approximated by the Equation (1) [5] where $F_{r}$ is the resonant frequency, $C$ is the light velocity.

$$
F_{r}=\frac{C}{4(\mathrm{Lp}+\mathrm{Wp}-\mathrm{Ws})}
$$

If there is another substrate different from Air, $C$ will be $C_{0} / \sqrt{\varepsilon_{r}}$ where $C_{0}=3 \times 10^{8} \mathrm{~m} / \mathrm{s}$. For our case, the space between the patch and the ground plan is essentially air minus a $0.8 \mathrm{~mm}$ FR4 epoxy layer.

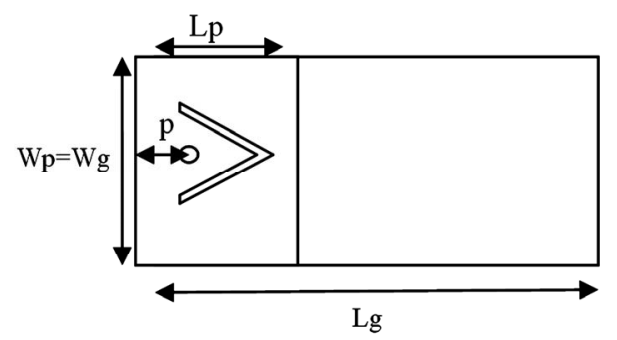

(a) Front view

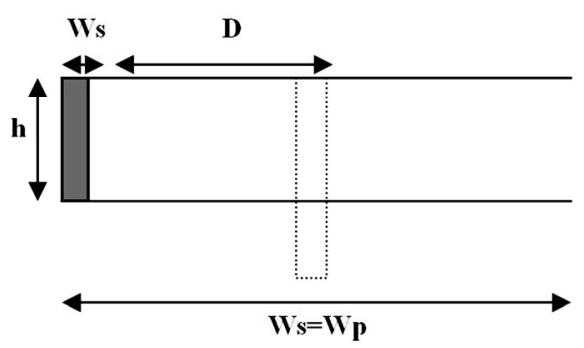

(b) Side view

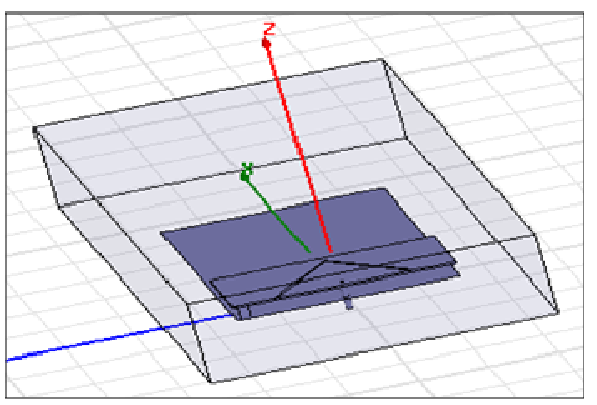

(c) Perspective view

Figure 1. Different view of the designed antenna.

To compute the resonant frequency, we have the following values: $\mathrm{Lp}=29.3 \mathrm{~mm}, \mathrm{Wp}=64 \mathrm{~mm}, \mathrm{Ws}_{\max }=3$ $\mathrm{mm}$. The theoretical $F_{r}$ is $830 \mathrm{MHz}$. The obtained frequency is then not far from $1920 \mathrm{MHz}$ the central frequency of GSM900 band. In fact, there is no equation to determine the resonant frequency for a PIFA that contains not only the patch dimensions but also the other parameters that can affect the antenna characteristics. For this, the author will make constant the patch dimensions that are the mean parameters can furnish the resonant frequency and he will vary undependably the other parameters (ground plan dimensions Lg, height of radiating plate $\mathrm{h}$, feeding point position $\mathrm{p}$, shorting plate Width Ws and position D).

\subsection{The Choice of the Simulator}

HFSS (High Frequency Simulator Structure) is a high performance full wave electromagnetic (EM) field simulator for arbitrary 3D volumetric passive device modeling that takes advantage of the familiar Microsoft Windows graphical user interface. It integrates simulation, visualization, solid modeling, and automation in an easy to 
learn environment where solutions to 3D EM problems are quickly and accurate obtained. Ansoft HFSS employs the Finite Element Method (FEM), adaptive meshing, and brilliant graphics to give unparalleled performance and insight to all of 3D EM problems. Ansoft HFSS can be used to calculate parameters such as S-Parameters, Resonant Frequency and Fields. Typical uses include Package Modeling, PCB Board Modeling, Mobile Communications (Patches, Dipoles, Horns, and Conformal Cell Phone Antennas), Specific Absorption Rate (SAR), Infinite Arrays, Radar Section (RCS), Frequency Selective Surface (FSS) and filters such Cavity Filters, Microstrip, Dielectric. HFSS is an interactive simulation system whose basic mesh element is a tetrahedron T. In industry, Ansoft HFSS is the tool of choice for High productivity research, development, and virtual prototyping [6].

The HFSS is then used in our simulation; the author proposes after exposing the results of the HFSS simulations.

\subsection{The Choice of the Height $h$}

The height $\mathrm{h}$ is the distance between the top plate and the ground plane. In order to eliminate the effects of the ground plane, the patched is placed on the edge of an infinite ground plane (in HFSS, the choice the infinite ground plan can made during defininig boundaries) at a height varying from $6 \mathrm{~mm}$ to $13 \mathrm{~mm}$. From the simulation result shown by Figure 2 for GSM900 band, the heights 10 and $11 \mathrm{~mm}$ present important $S_{11}$ values and closer to central frequency. It is then necessary to look if they are adequate to DCS band also. From result shown in Figure 3, h $=11 \mathrm{~mm}$ is a very interesting height (it will be nearly the handset thickness).

\subsection{The Choice of the Ground Plan Length Lg}

The height $\mathrm{h}$ is taken equal to $11 \mathrm{~mm}$. Then, a variation of the ground plane length $\mathrm{Lg}$ is made from $70 \mathrm{~mm}$ to $120 \mathrm{~mm}$. This sweep is taken because the designed antenna will be mounted on a GSM handset. The Figures 4 and 5 show the result of the parametric simulation. The curve corresponding to the length $80 \mathrm{~mm}$ is the most adapted (the closest to DCS central frequency and is a $S_{11}$ peak for GSM900). In reality, the simulation shows close results for the lengths $80 \mathrm{~mm}, 90 \mathrm{~mm}$ and $100 \mathrm{~mm}$. Also, $120 \mathrm{~mm}$ and over can be considered not interesting values for a ground plane in a handset. Then, $\mathrm{Lg}=80 \mathrm{~mm}$. In the following, the other parameters effects are discussed.

\subsection{The Choice the Shorting Plate Position D, Width Ws and Feeding Point Position}

The three parameters D, Ws and $p$ have approximatively comparable effect intensity. Theses parameters will vary simultaneously. The shorting plate position D from 28 $\mathrm{mm}$ to $31 \mathrm{~mm}$, the width Ws from 1 to $3 \mathrm{~mm}$, the feeding point $\mathrm{p}$ from 3 to $7 \mathrm{~mm}$ from the patch edge. The number of possible configuration is $4 \times 3 \times 5=60$. The intervall sweep must be chosen correctly if not the simulation can be costly in computing and memories ressources. The Figure 4 shows the results of the tri-parametric simulation for GSM900 band. From Figure 4, there is a curve

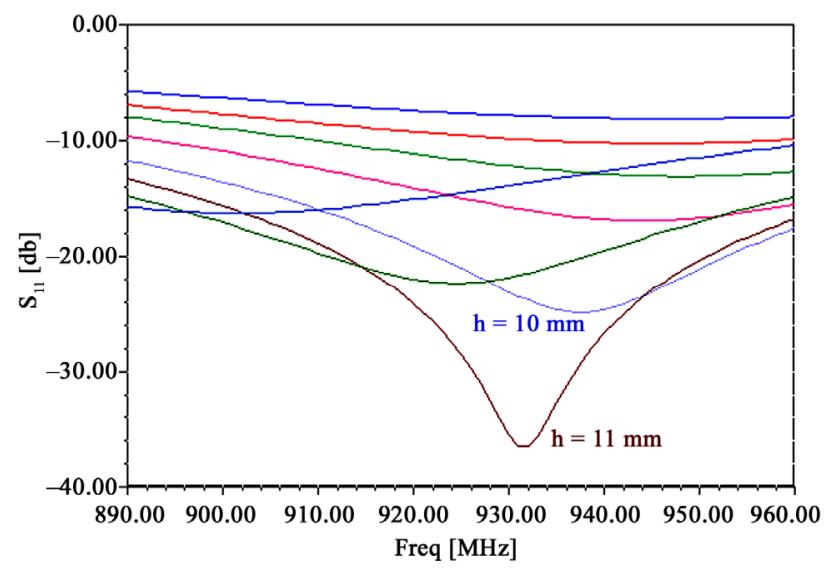

Figure 2. h-parametric simulation for GSM band.

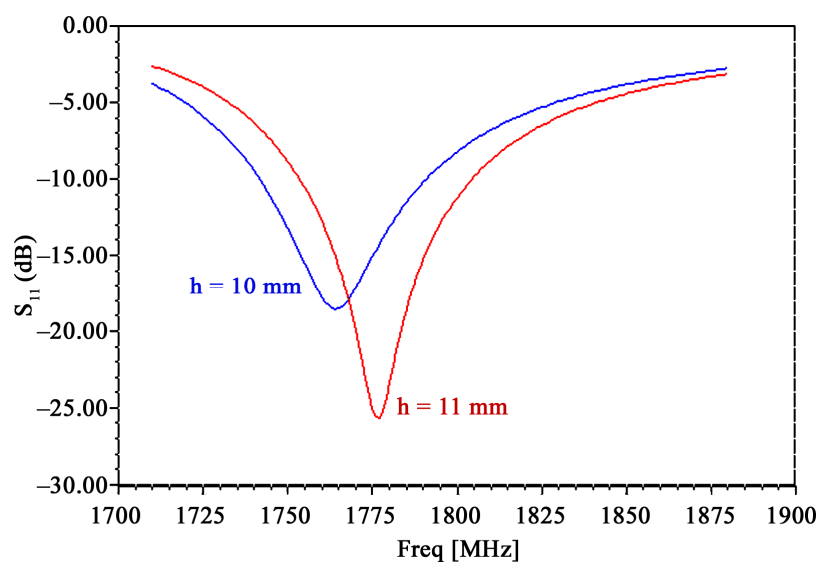

Figure 3. h-parametric simulation for DCS.

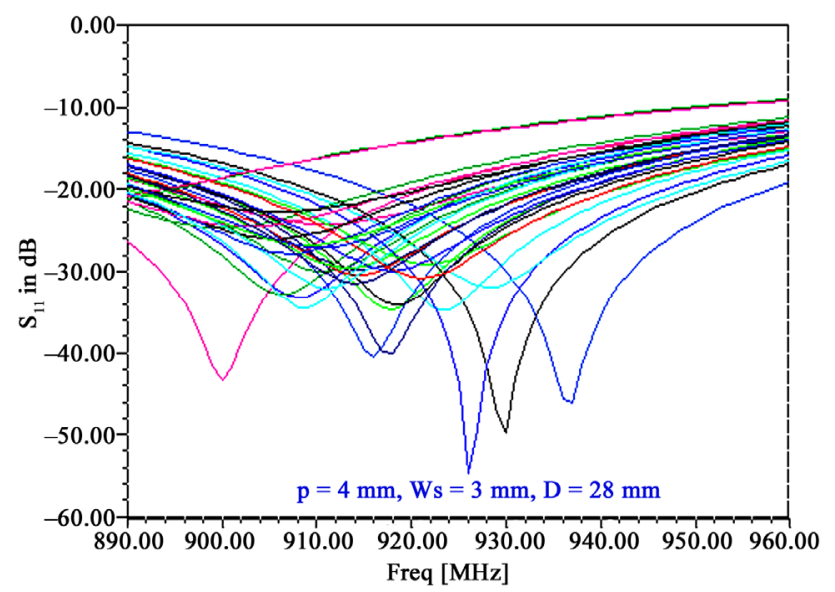

Figure 4. Tri-parametric simulation for GSM900 band. 
that present minimal $S_{11}$ values and very close to the central frequency $926 \mathrm{MHz}$. The corresponding configuration is ( $\mathrm{p}=4 \mathrm{~mm}, \mathrm{D}=28 \mathrm{~mm}, \mathrm{Ws}=3 \mathrm{~mm}$ ). It's now important to check the simulation result for DCS band. The result is shown in Figure 5. Except of some values, the effect of different parameters are very close in this band. It is then easy to verify that our chosen configuration for GSM is also adequate for DCS band. The result shown by Figure 6 is interesting because it presents a $S_{11}$ peak near $1800 \mathrm{MHz}$.

\section{The Designed Antenna Characterization}

The dimensions of the designed bi-band antenna are summarized in the Table 1. We will now present the antenna characteristics.

\subsection{The Reflection Loss}

The Figure 7 shows the $S_{11}$ parameter function of frequency in $[0-2.4 \mathrm{GHz}]$.

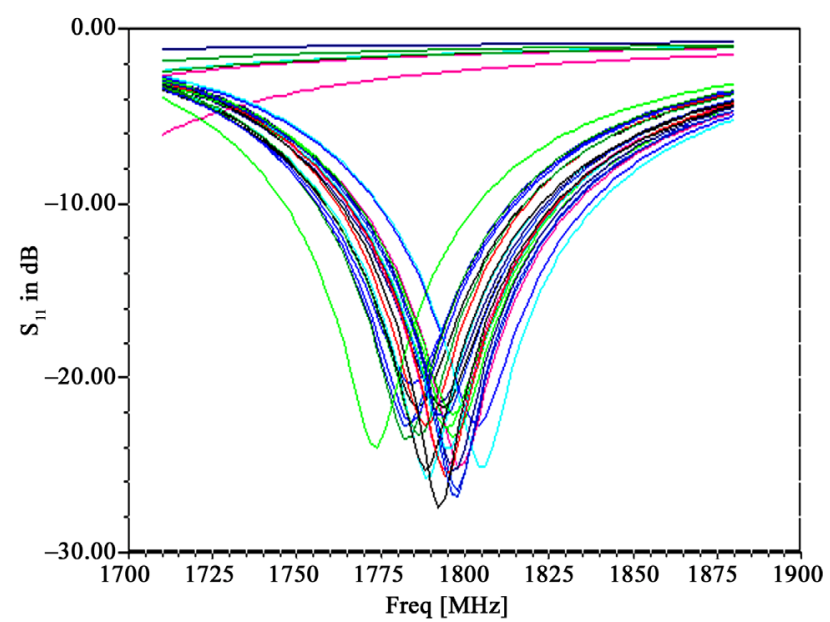

Figure 5. Tri-parametric simulation for DCS band.

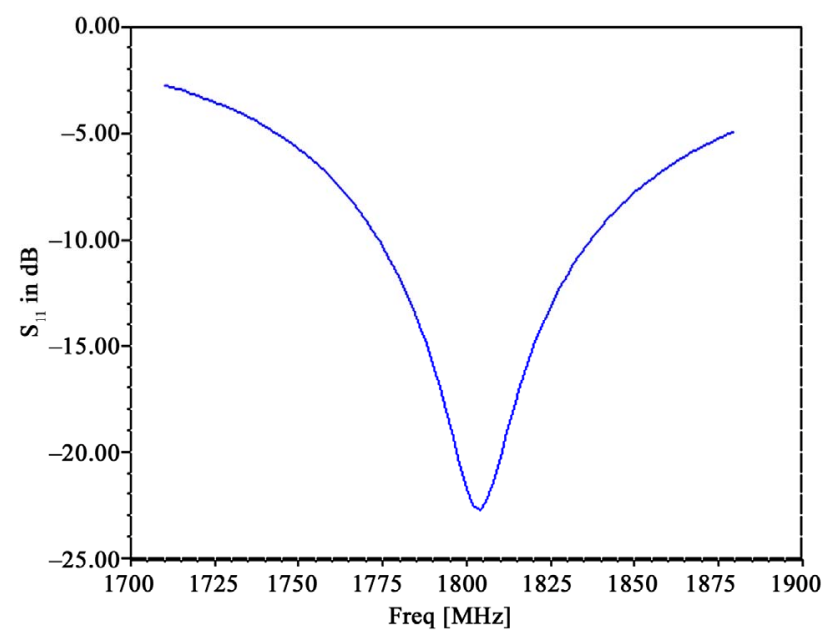

Figure 6. The chosen configuration in DCS band.
Table 1. The designed antenna dimensions.

\begin{tabular}{cc}
\hline Antenna parameter & Value of the parameter $(\mathrm{mm})$ \\
\hline Patch length Lp & 64.3 \\
Patch width Wp & 80 \\
Ground plan length Lg & 64 \\
Ground plan width Wg & 11 \\
Height h & 3 \\
Short plate width Ws & 28 \\
Short plate position D & 4 \\
\hline
\end{tabular}

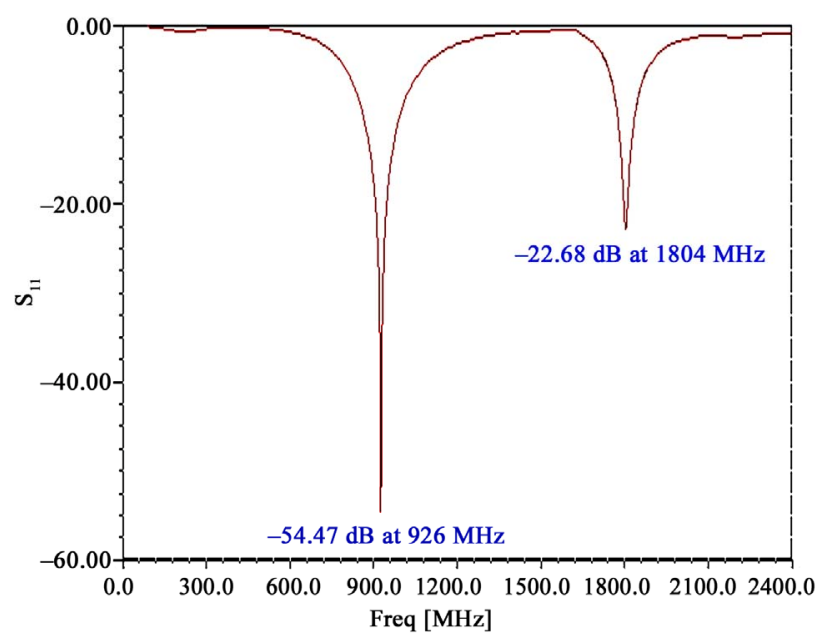

Figure 7. $\mathrm{S}_{11}$ depending on frequency for [0 - $\left.2400 \mathrm{MHz}\right]$.

There are two peaks of $S_{11}$ parameter in the curve of Figure 7. The first peak is around $926 \mathrm{MHz}$ (very close to the GSM900 central frequency $925 \mathrm{MHz}$ ), and the second peak is around $1804 \mathrm{MHz}$ (very close to the DCS central frequency $1995 \mathrm{MHz}$ ). Also, the $\mathrm{S}_{11}$ values out of both bands are near 0 . That means the designed antenna can't interfere with other radiations. We can also run the simulation by refining the sweep interval for more precision. As given exactly by simulations tables, we note $S_{11}$ $=-14.71 \mathrm{~dB}$ for $890 \mathrm{MHz}$ (the low frequency of the GSM900 band), $\mathrm{S}_{11}=-15.68 \mathrm{~dB}$ for $960 \mathrm{MHz}$ (the high frequency of the GSM900 band), $S_{11}=-3 \mathrm{~dB}$ for 1710 $\mathrm{MHz}$ (the low frequency of the DCS band), $\mathrm{S}_{11}=-5 \mathrm{~dB}$ for $1880 \mathrm{MHz}$ (the high frequency of the DCS band). The designed antenna has a $S_{11}$ litter than $-14.71 \mathrm{~dB}$ for the first band and better than $-3 \mathrm{~dB}$ for second band. 


\subsection{The VSWR and Bandwidth the Diagram Pattern}

We obtain as shown in Figure 8 for GSM900 band a $\operatorname{VSWR}=1.45$ for $890 \mathrm{MHz}$ (the lowest frequency), $\mathrm{VSWR}_{\min }=1.003$ for $926 \mathrm{MHz}$ (the resonant frequency), $\mathrm{VSWR}=1.39$ for $960 \mathrm{MHz}$ (the highest frequency). The VSWR is at its minimum. It's a very interesting result. Also, The GSM bandwidth $(70 \mathrm{MHz})$ is for the designed antenna a 1:1.45 VSWR bandwidth and the antenna presents a 1:2 bandwidth equal to $140 \mathrm{MHz}$. It is considered a very interesting result. Also, we obtain as shown in Figure 9 for DCS band a VSWR $=6.39$ for $1710 \mathrm{MHz}$ (the lowest frequency), $\mathrm{VSWR}_{\min }=1.15$ for $1922 \mathrm{MHz}$ (the resonant frequency), VSWR $=3.62$ for $1880 \mathrm{MHz}$ (the highest frequency). The VSWR is at its minimum for the resonant frequency. It's a very interesting result. Also, the antenna presents a 1:2 VSWR bandwidth equal to $70 \mathrm{MHz}$.

\subsection{The Smith Chart}

The Figure 10 shows a regular Smith chart with intersting parameters of reflection, impedance, VSWR, and Q.

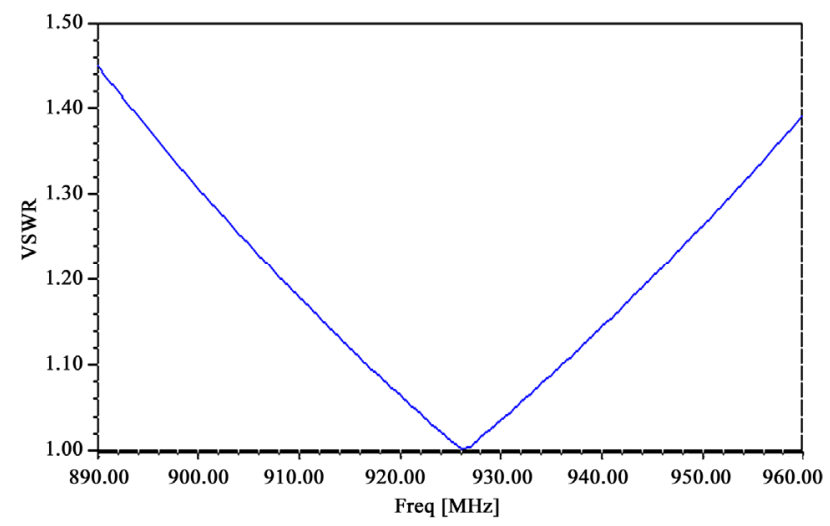

Figure 8. VSWR depending on the frequency for the GSM900 band.

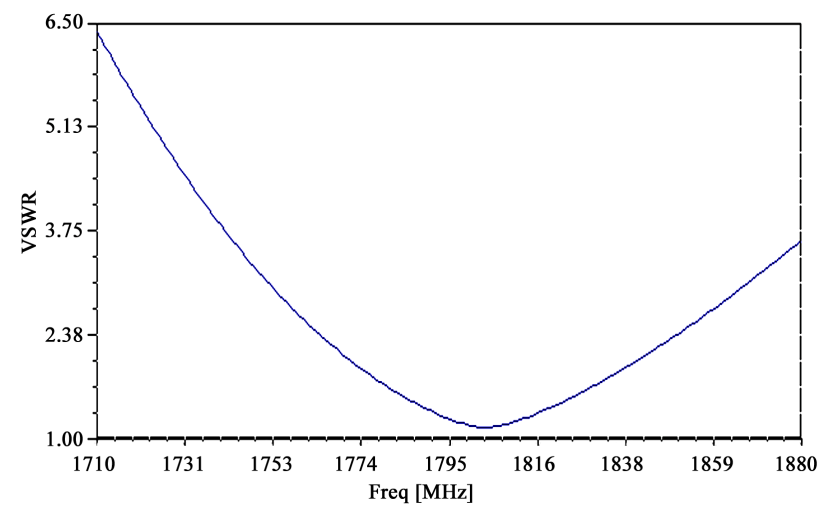

Figure 9. The VSWR depending on the frequency for the DCS1800 band.

\subsection{The Impedance in the Feeding Point}

From the Table 2 and Figure 10, we can see very close values between the impedances (port impedance $Z_{0}$ and feeding point impedance). The feeding point position is then confirmed that is compliant because it presents a very interesting adaptation.

\subsection{The Antenna Parameters}

The simulations results shown in Figure 11 give the antenna parameters. The obtained peak gain $\mathrm{G}$ is $12.84 \mathrm{~dB}$ and peak directivity equal to $15.16 \mathrm{~dB}$; the radiation efficiency is 0.847 . We can confirm by the Figure 12 that (xz) is the E-plane and its maximum is for (phi $=0 \mathrm{deg}$ and theta $=0 \mathrm{deg}$ ). Also, the antenna has regular polar diagram as shown in Figure 13.

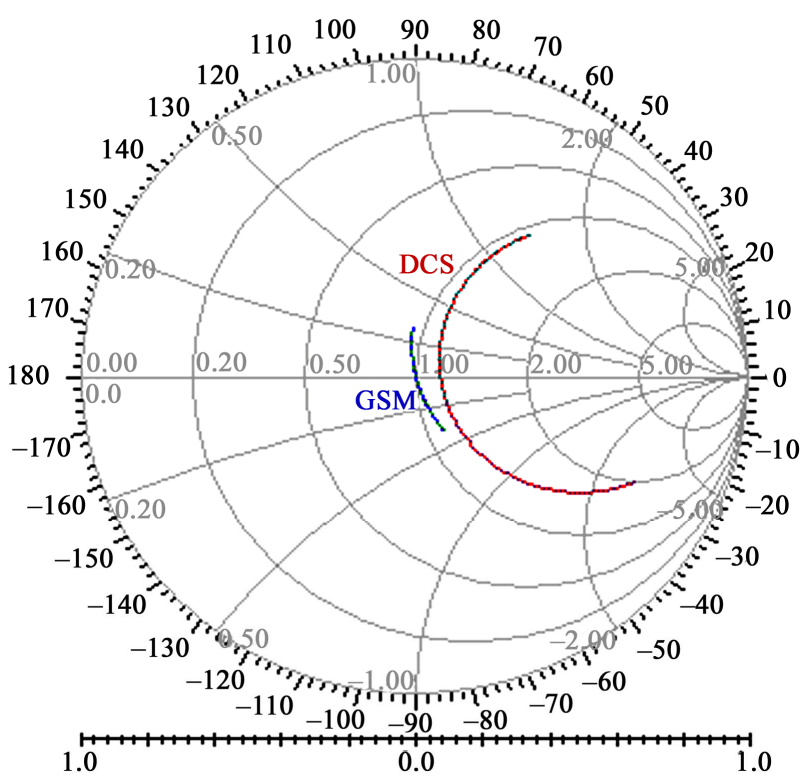

Figure 10. The impedance smith chart for both bands.

Table 2. The impedances table.

\begin{tabular}{ccc}
\hline $\begin{array}{c}\text { Frequency } \\
(\mathrm{MHz})\end{array}$ & $\begin{array}{c}\text { Impedance } \mathrm{Z} \\
\text { (Magnitude in dB) }\end{array}$ & $\begin{array}{c}\text { Port impedance } \mathrm{Z}_{0} \\
\text { (Magnitude in dB) }\end{array}$ \\
\hline 890 & 41.40 & 35.24 \\
927 & 35.24 & 35.24 \\
960 & 34.64 & 35.24 \\
1710 & 7.59 & 35.24 \\
1809 & 40.53 & 35.24 \\
1880 & 63.07 & 35.24 \\
\hline
\end{tabular}




\begin{tabular}{|c|c|c|c|}
\hline \multicolumn{4}{|c|}{ Antenna Parameters: } \\
\hline & Quantity & Value & Units \\
\hline & Max U & 0.81059 & $\mathrm{~W} / \mathrm{sr}$ \\
\hline & Peak Directivity & 15.166 & \\
\hline & Peak Gain & 12.846 & \\
\hline & Peak Realized Gain & 10.186 & \\
\hline & Radiated Power & 0.67167 & w \\
\hline & Accepted Power & 0.79298 & w \\
\hline & Incident Power & 1 & w \\
\hline & Radiation Efficiency & 0.84702 & \\
\hline & Decay Factor & 0 & \\
\hline
\end{tabular}

Figure 11. Antenna parameters as given by HFSS.

\begin{tabular}{|c|c|c|c|c|}
\hline \multicolumn{5}{|l|}{ Maximum Field Data: } \\
\hline IE Field & Value & |Units & At Phi & At Theta \\
\hline Total & 24.722 & $\mathrm{~V}$ & 360deg & Odeg \\
\hline$x$ & 24.722 & V & 360deg & Odeg \\
\hline$Y$ & 2.4191 & V & 310deg & 40deg \\
\hline$z$ & 6.2508 & V & 10deg & 30deg \\
\hline Phi & 24.722 & V & 270deg & Odeg \\
\hline Theta & 24.722 & $\mathrm{v}$ & 360deg & Odeg \\
\hline LHCP & 17.481 & V & 350deg & Odeg \\
\hline $\mathrm{RHCP}$ & 17.481 & V & 330deg & Odeg \\
\hline Ludwig $3 / X$ dominant & 24.722 & V & 360deg & Odeg \\
\hline Ludwig $3 / Y$ dominant & 1.3207 & $\mathrm{~V}$ & 310deg & 40deg \\
\hline
\end{tabular}

Figure 12. Maximum field data as given by HFSS.
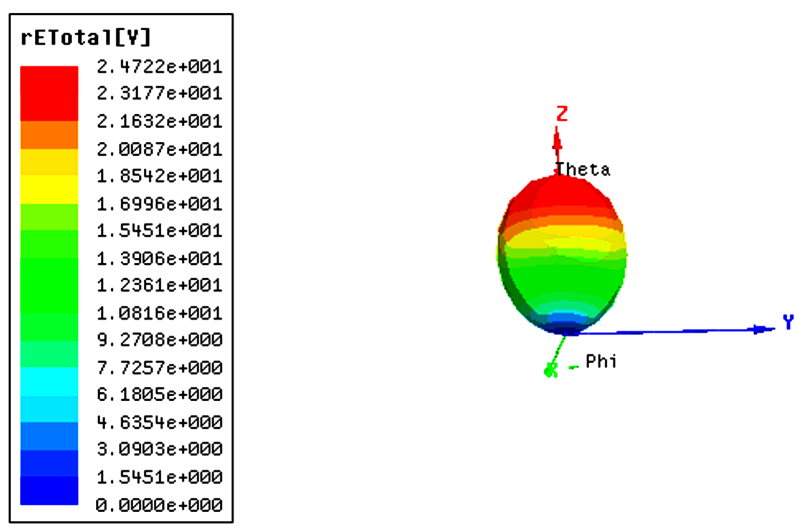

Figure 13. The E-field 3D polar diagram pattern.

\section{Conclusions}

To design a bi-band PIFA for GSM900/DCS1800 bands, the author adopted a methodology based on parametric simulations. The design process allows the following conclusions:

1) The PIFA characteristics are affected by each of the changed parameter (the height of the radiating plate, the ground plane length, the position and width of the short plate, the position of the feeding point) in compatibility with precedent studies [7].
Table 3. The design antenna parameters and dimensions.

\begin{tabular}{ll}
\hline \multicolumn{1}{c}{ Antenna parameter } & \multicolumn{1}{c}{$\begin{array}{c}\text { Value of the parameter } \\
\text { GSM900, DCS1800 }\end{array}$} \\
\hline Patch Length Lp & $29.3 \mathrm{~mm}$ \\
Patch width Wp & $64 \mathrm{~mm}$ \\
Ground plan length Lg & $80 \mathrm{~mm}$ \\
Ground plan width Wg & $64 \mathrm{~mm}$ \\
Height h & $11 \mathrm{~mm}$ \\
Short plate width Ws & $3 \mathrm{~mm}$ \\
Short plate position D & $28 \mathrm{~mm}$ \\
Feeding point position & $4 \mathrm{~mm}$ \\
Resonnat frequency & $926 \mathrm{MHz}, 1804 \mathrm{MHz}$ \\
Peak S & $-54.5 \mathrm{~dB},-22.7 \mathrm{~dB}$ \\
1:1.2 VSWR bandwith & $140 \mathrm{MHz}, 70 \mathrm{~dB}$ \\
Peak Gain & $12.85 \mathrm{~dB}$ \\
Peak Directivity & $15.17 \mathrm{~dB}$ \\
E total max & $85 \%$ \\
\hline
\end{tabular}

2) It's interesting in the design of the PIFA to search an effective solution not the optimal one. In fact, difference will be very little (like for DCS but not GSM) and also, the values of the PIFA dimensions must be practical (one decimal) not theoretical. The Important is the fact that the solution respects the requirements.

3) We must look for a solution compliant simultanously for both bands. In fact, during simulation, an enhancement in one band affects negativly an other band. A trade-off solution was chosen.

4) The designed PIFA for GSM use respects the requirements especially for the resonant frequency, the VSWR, the bandwidth, the reflection coefficient, the anisotropy and the miniaturization. A bandwidth enhancement for DCS band can be handled.

5) In comparison with precedent designed PIFA [3,4] for different frequency bands, the antenna presents a very high gain and directivity and also an interesting radiation efficiency.

The Table 3 summarizes the characteristics and dimensions of the designed antenna. The analysis of those results makes from our designed antenna a succeeded trade-off that respects GSM requirements. 


\section{REFERENCES}

[1] K. L. Wong, "Introduction and Overview," In: K. L. Wong, Ed., Planar Antennas for Wireless Communications, J. Willy and Sons, Hoboken, 2003, p. 1

[2] K. L. Virga and Y. Rahmat-Samii, "Low-Profile Enhanced Bandwith PIFA for Wireless Communications Packaging," IEEE Transactions on Microwave Theory and Techniques, Vol. 45, No. 10, 1997, pp. 1879-1888. doi:10.1109/22.641786

[3] W.-J. Liao, T.-M Liu and S.-Y. Ho, "Miniaturized PIFA Antenna for $2.4 \mathrm{GHz}$ ISM Band Applications," IEEE Proceedings of the 6th European Conference on Antennas and Propagation (EUCAP), Prague, March 2012, pp. 3034-3037.
[4] A. K. Skrivervik, J.-F. Zürcher, O. Staub and J. R. Mosig, "PCS Antenna Design: The Challenge of Miniaturization," IEEE Antennas and Propagation Magazine, Vol. 43, No. 4, 2001, pp. 12-27. doi:10.1109/74.951556

[5] PIFA: The Planer Inverted F Antenna. http://www.antenna-theory.com/antennas/patches/pifa.ph $\mathrm{p}$

[6] Ansoft Corporation, "HFSS 10.0 User's Guide," Ansoft Corporation, Pittsburg, 2005.

[7] H. T. Chattha, Y. Huang, M. K. Ishfaq and S. J. Boyes, "A Comprehensive Parametric Study of Planar Inverted-F Antenna," Wireless Engineering and Technology, Vol. 3, 2012, pp. 1-11. doi:10.4236/wet.2012.31001 